\title{
Optical Indices of Lithiated Electrochromic Oxides
}

M. Rubin, K. von Rottkay, S-J. Wen, N. Ozer, and J. Slack Energy and Environment Division

\section{RECEIVED}

FFR 261997

OSTI

September 1996

Presented at the

SPIE International

Symposium on Optical

Materials Technology for

Energy Efficiency and Solar

Energy Conversion $X V$,

Freiburg, Germany,

September 16-19; 1996, and to be published in the Proceedings
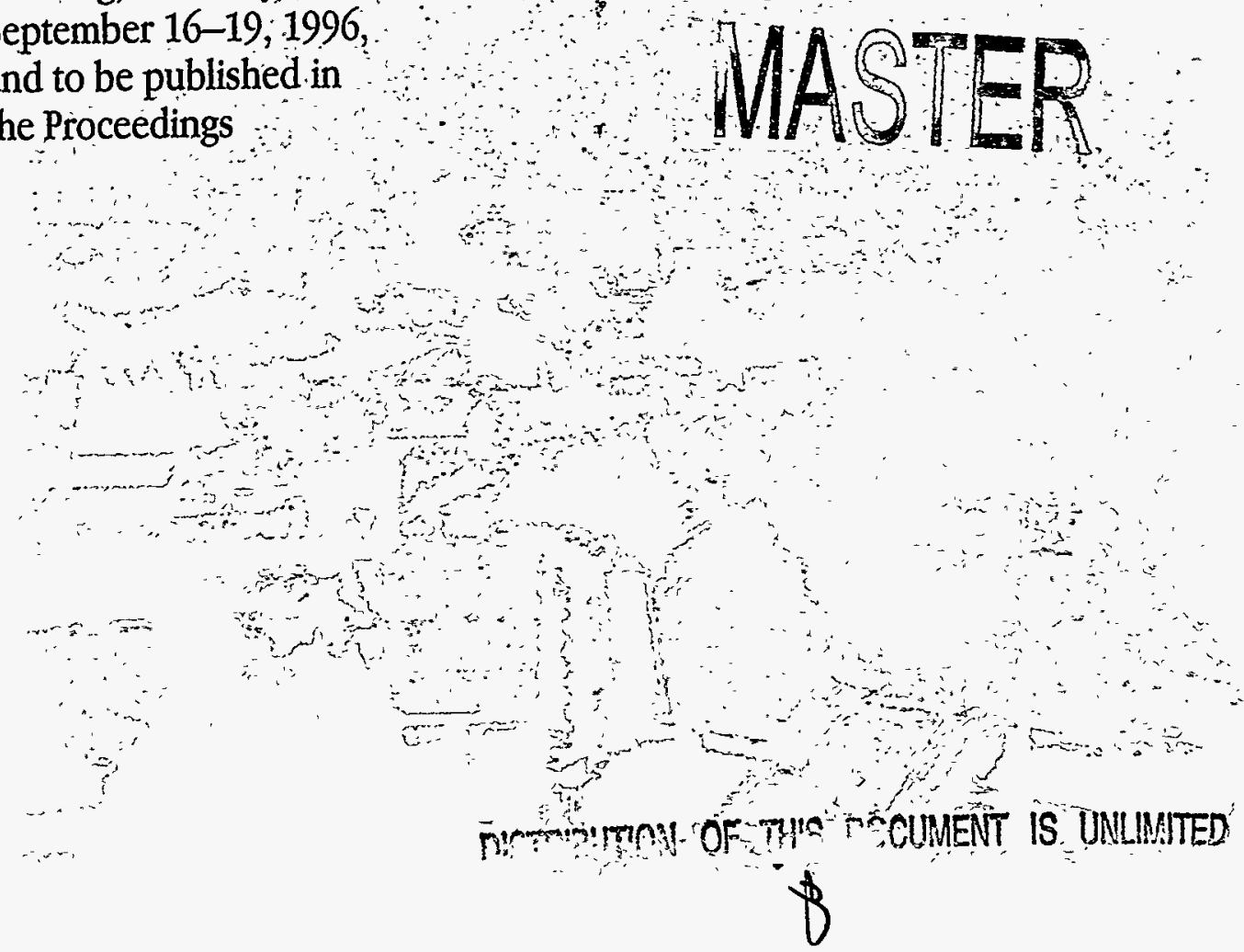


\section{DISCLAIMER}

This document was prepared as an account of work sponsored by the United States Government. While this document is believed to contain correct information, neither the United States Government nor any agency thereof, nor The Regents of the University of California, nor any of their employees, makes any warranty, express or implied, or assumes any legal responsibility for the accuracy, completeness, or usefulness of any information, apparatus, product, or process disclosed, or represents that its use would not infringe privately owned rights. Reference herein to any specific commercial product, process, or service by its trade name, trademark, manufacturer, or otherwise, does not necessarily constitute or imply its endorsement, recommendation, or favoring by the United States Government or any agency thereof, or The Regents of the University of California. The views and opinions of authors expressed herein do not necessarily state or reflect those of the United States Government or any agency thereof, or The Regents of the University of Califomia.

Ernest Orlando Lawrence Berkeley National Laboratory is an equal opportunity employer. 
Presented at SPIE's International Symposium on Optical Materials Technology for Energy Efficiency and Solar Energy Conversion XV, Freiburg, Germany (September 1996) and to be published in the proceedings.

\title{
Optical Indices of Lithiated Electrochromic Oxides
}

M. Rubin, K. von Rottkay, S-J. Wen, N. Ozer, and J. Slack

\author{
Building Technologies Program \\ Energy and Environment Division \\ Lawrence Berkeley National Laboratory \\ University of California \\ Berkeley, CA 94720
}

September 1996

This work was supported by the Assistant Secretary for Energy Efficiency and Renewable Energy, Office of Building Technology, State and Community Programs (BTS), Office of Building Systems of the U.S. Department of Energy under Contract No. DE-AC03-76SF00098. 


\section{DISCLAIMER}

Portions of this document may be illegible in electronic image products. Images are produced from the best available original document. 


\title{
Optical Indices of Lithiated Electrochromic Oxides
}

\author{
M. Rubin, K. von Rottkay, S.-J. Wen, N. Ozer, J. Slack, \\ Lawrence Berkeley National Laboratory, University of California, Berkeley, CA 94720 \\ Tel: 510-486-7124, Fax: 510-486-6099,E-Mail: MDRubin@lbl.gov.
}

\begin{abstract}
Optical indices have been determined for thin films of several electrochromic oxide materials. One of the most important materials in electrochromic devices, $\mathrm{WO}_{3}$, was thoroughly characterized for a range of electrochromic states by sequential injection of $\mathrm{Li}$ ions. Another promising material, $\mathrm{Li}_{0.5} \mathrm{Ni}_{0.5} \mathrm{O}$, was also studied in detail. Less detailed results are presented for three other common lithium-intercalating electrochromic electrode materials: $\mathrm{V}_{2} \mathrm{O}_{5}$, $\mathrm{LiCOO}$, and $\mathrm{CeO}_{2}-\mathrm{TiO}_{2}$. The films were grown by sputtering, pulsed laser deposition (PLD) and sol-gel techniques. Measurements were made using a combination of variable-angle spectroscopic ellipsometry and spectroradiometry. The optical constants were then extracted using physical and spectral models appropriate to each material. Optical indices of the underlying transparent conductors, determined in separate studies, were fixed in the models of this work. The optical models frequently agree well with independent physical measurements of film structure, particularly surface roughness by atomic force microscopy. Inhomogeneity due to surface roughness, gradient composition, and phase separation are common in both the transparent conductors and electrochromics, resulting sometimes in particularly complex models for these materials. Complete sets of data are presented over the entire solar spectrum for a range of colored states. This data is suitable for prediction of additional optical properties such as oblique transmittance and design of complete electrochromic devices.
\end{abstract}

\section{INTRODUCTION}

The complex refractive index of electrochromic materials and other materials used in electrochromic devices is needed for design and optimization. Although reports on radiometric properties of electrochromic materials, primarily visible transmittance, are extensive, complete sets of optical constants are scarce. Even for $\mathrm{WO}_{3}$, the most widely used and studied electrochromic material, available information on optical indices has been incomplete. For all other materials the volume of data falls off rapidly. The most common limitations of existing data are in spectral and electrochemical range. The situation is further complicated by the fact that there are notable variations in properties for nominally similar materials. These variations may be due to composition, density, surface roughness and even thickness.

In this work, we survey materials that intercalate $\mathrm{Li}$ ions including $\mathrm{WO}_{3}$. We not only characterize the extreme bleached and colored states, but also a range of intermediate charge states for several of these materials. This is very important in design and optimization studies because of the need to achieve a balance between cooling and lighting.' The spectral range of our measurements typically spans the entire solar spectrum from 300 to $2500 \mathrm{~nm}$. We attempt to make the models of structure and dispersion used to analyze the optical data consistent with the physical nature of the materials. A subtheme of this work is the effect of surface morphology which is an outcome of our attempts to validate the models with direct AFM observations of roughness. We recently made a first attempt to model a . complete device including transparent conductors. ${ }^{2}$

\section{METHODS}

The films studied in this paper were grown by sputtering, pulsed laser deposition and sol-gel techniques under a wide variety of conditions. Specific details are noted for each section. PLD has been an especially useful technique because samples can be grown rapidly and the targets are small and thus easy to fabricate. The films are usually dense and smooth. Perhaps most important, control of stoichiometry is easier than with sputtering, where various ion and neutral-beam effects complicate the process. The disadvantage of PLD for this application is that is it not amenable to scale up. We have found, however, that a rapidly optimized film made once by PLD can usually be recreated by other techniques.

Primary optical measurements were made with a variable-angle spectroscopic ellipsometer (VASE) from $250 \mathrm{~nm}$ to $1000 \mathrm{~nm}$ using an instrument from the J.A. Woollam Co. In order to cover the whole solar spectrum, transmittance 
and reflectance measurements from $250 \mathrm{~nm}$ to $2500 \mathrm{~nm}$ were added; these measurements were taken at near-normal incidence on a Perkin-Elmer Lambda 19 spectrophotometer. Structural models were then constructed for each material usually with a surface roughness layer. Dispersion was usually represented by one or more Lorentz oscillators. In the case of $\mathrm{WO}_{3}$, Gaussian forms were used which should actually correspond better to the strongly inhomogeneous broadening expected for most of the electrochromic bands in these materials. ${ }^{3}$ The main improvement was found in the region just above the band gap of $\mathrm{WO}_{3}$, where a Gaussian broadening of the oscillator describes the relatively abrupt absorption edge better than homogeneous Lorentzian broadening.

To examine the electrochromic behavior $\mathrm{Li}$ was inserted into the films in a liquid cell. The cell consisted of the electrochromic working electrode on transparent conductor, a lithium counterelectrode and a lithium reference electrode in an electrolytic solution of $1 \mathrm{MLiPF}_{6}$ in propylene carbonate and ethylene carbonate (7:3). The water content of the $\mathrm{LiPF}_{6}$ solution was smaller than $1 \mathrm{ppm}$. Lithiation was performed in the galvanostatic mode so that transported charge could be determined accurately by the time of charging. To ensure coloration reversibility, cyclic voltammetry was performed for about 100 cycles relative to the lithium reference electrode with scan rates between 1 $\mathrm{mV} / \mathrm{s}$ and $20 \mathrm{mV} / \mathrm{s}$.

Ellipsometric and radiometric measurements were made at coloration states corresponding to injected volumetric charge densities. These values were obtained from the areal charge densities determined directly by electrical charge measurements and the thickness of each individual film. Film thickness was measured by surface profilometry. The thickness was subsequently refined using ellipsometry (see next section). The use of the volumetric charge density as the parameter to normalize for thickness is deliberate; the extinction coefficient should not then depend on thickness. For the case of $\mathrm{WO}_{3}$, we find negligible dependence of the refractive index of $\mathrm{WO}_{3}$ films on thickness over the thickness range of interest for electrochromic applications. ${ }^{4}$ We assume that all the injected charge is actually intercalated into the electrochromic film onto optically active sites. This should be a good assumption within safe voltage limits, slow scan rates and charge density below saturation.

\section{RESULTS}

\subsection{Transparent Conductors}

In order to model complete electrochromic devices, we must of course have the properties of the transparent conducting layers, typically $\mathrm{SnO}_{2}: \mathrm{F}$ (we use Tech $15^{\mathrm{TM}}$ made by Libbey-Owens-Ford) or $\mathrm{In}_{2} \mathrm{O}_{3}: \mathrm{Sn}$ (ITO). These materials have recently been studied in sufficient detail to make full solar spectral calculations. ${ }^{5.67}$ Furthermore, we could not put the electrochromic materials of this paper into colored states without depositing them on transparent conductors. So we must have good values of optical indices for the transparent conductors at the outset to incorporate into our optical models or the results for the electrochromic materials will be in error.

\section{$3.2 \mathrm{WO}_{3}$}

The complex refractive index was determined from $300 \mathrm{~nm}$ to $2500 \mathrm{~nm}$ as a function of intercalated charge density. because its complex refractive index increases with injected charge (Figure 1). Recently, we summarized the work done on $\mathrm{WO}_{3}$ and prepared a detailed set of optical index data. ${ }^{4}$
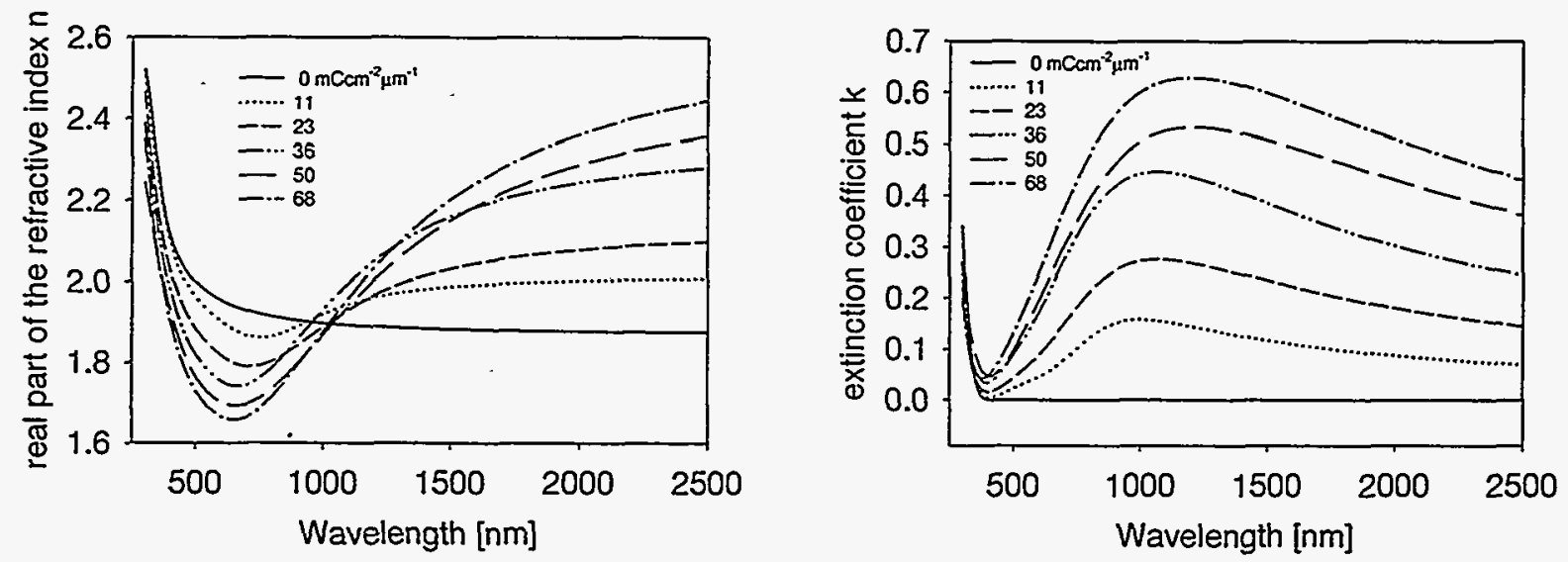

Figure 1. Real and imaginary parts of the refractive index of $\mathrm{WO}_{3}$ as a function of charge density. 


\section{3 $\mathrm{Li}_{\mathrm{x}} \mathrm{Ni}_{1 \cdot \mathrm{x}} \mathrm{O}$}

Details of deposition, physical and electrochemical properties of $\mathrm{Li}_{x} \mathrm{Ni}_{1-x} \mathrm{O}$ are beyond the scope of this paper and have been published separately. ${ }^{8} \mathrm{We}$ observe that $\mathrm{Li}_{x} \mathrm{Ni}_{1-x} \mathrm{O}$ films deposited by PLD are generally quite smooth, with lower $\mathrm{O}_{2}$ pressures resulting in the smoothest films. The exceptionally smooth film of Figure $2 \mathrm{a}$ as deposited at $60 \mathrm{mTorr}$ is far better in its electrochromic properties that the rougher film deposited at $200 \mathrm{mTorr}$. This result runs counter to the frequent supposition that rougher, more open films will intercalate charge more readily.
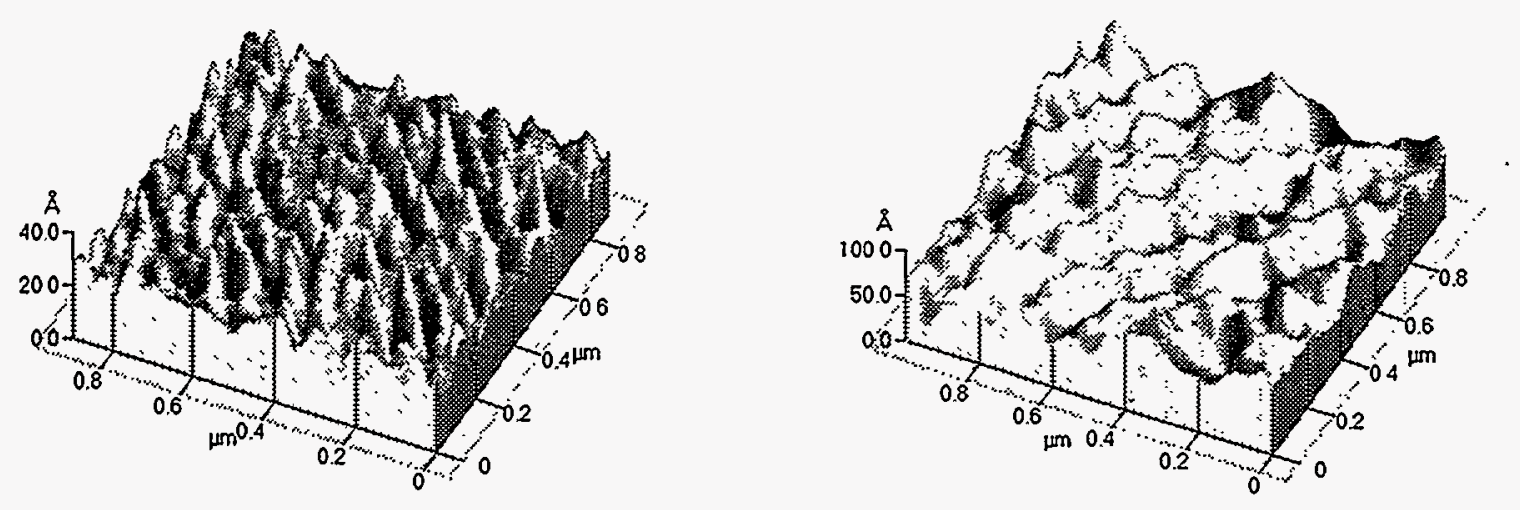

Figure 2. Surface image by $A F M$ of $\mathrm{Li}_{x} \mathrm{Ni}_{1-x} \mathrm{O}$ at a) $60 \mathrm{mT}$ oxygen pressure, rms roughness $4 \AA$; b) $200 \mathrm{mT}$ oxygen pressure, ims roughness $14 \AA$

Extremely good films near the stoichiometric composition of $\mathrm{Li}_{0.5} \mathrm{Ni}_{0.5} \mathrm{O}$ were made by PLD. Sputtered films were also made farther from stoichiometry and $\mathrm{NiO}$ films have been made which require an electrochemical formatting process to achieve full electrochromic performance. ${ }^{2}$ Despite the wide variation possible in this type of material, we feel that the PLD films represent the optimum achievable properties and so the data presented here will have some permanence as reference values.
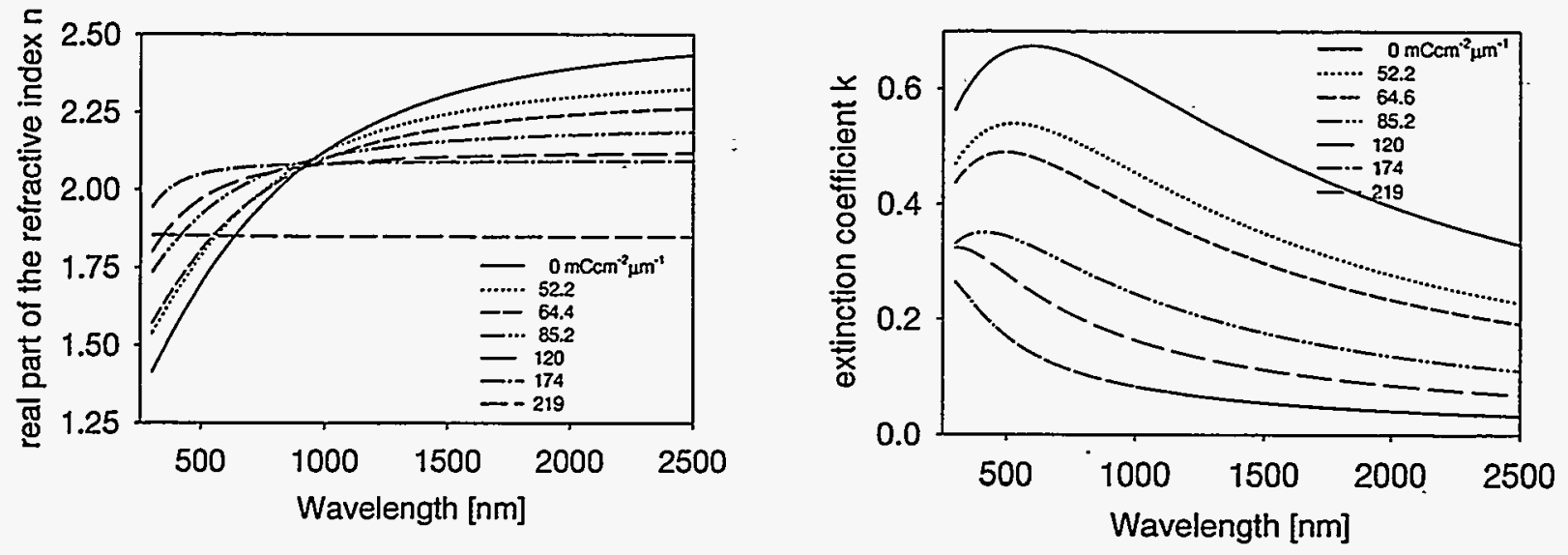

Figure 3. Optical indices of $\mathrm{Li}_{x} \mathrm{Ni}_{1-\mathrm{x}} \mathrm{O}$ deposited by PLD at $60 \mathrm{mTorr}_{2}$ : a) real and b) imaginary parts.

\section{4 $\mathrm{Li}_{\mathrm{x}} \mathrm{CoO}_{2}$ by PLD}

PLD Li $\mathrm{CoO}_{2}$ films were grown over a range of oxygen pressures from $20-200 \mathrm{mTorr}$. $\mathrm{Like} \mathrm{Li}_{\mathrm{x}} \mathrm{Ni}_{1-x} \mathrm{O}$ they show increasing surface absorption of $\mathrm{H}_{2} \mathrm{O}$, and $\mathrm{Li}_{2} \mathrm{CO}_{3}$ species with increasing $\mathrm{O}_{2}$ pressure. Increasing $\mathrm{Li}$ content in the films with increasing $\mathrm{O}_{2}$ deposition pressure, as in the case of $\mathrm{Li}_{x} \mathrm{Ni}_{1-x} \mathrm{O}$, may be the cause of this surface reaction. The AFM images of the $\mathrm{Li}_{x} \mathrm{CoO}_{2}$ films are similar in appearance to the $\mathrm{Li}_{x} \mathrm{Ni}_{1-x} \mathrm{O}$ films of Figure 4, but with 
increased roughness and the roughness again increases with pressure. So, increased absorbing area with pressure may be a simpler explanation. The most electrochemically active film was deposited at $50 \mathrm{mTorr} \mathrm{O}_{2}$ pressure by PLD from a $\mathrm{LiCoO}_{2}$ target and was almost as smooth as the $\mathrm{Li}_{x} \mathrm{Ni}_{1-\mathrm{x}} \mathrm{O}$ film at 60 mTorr ( $8 \AA$ compared to $4 \AA$ ).
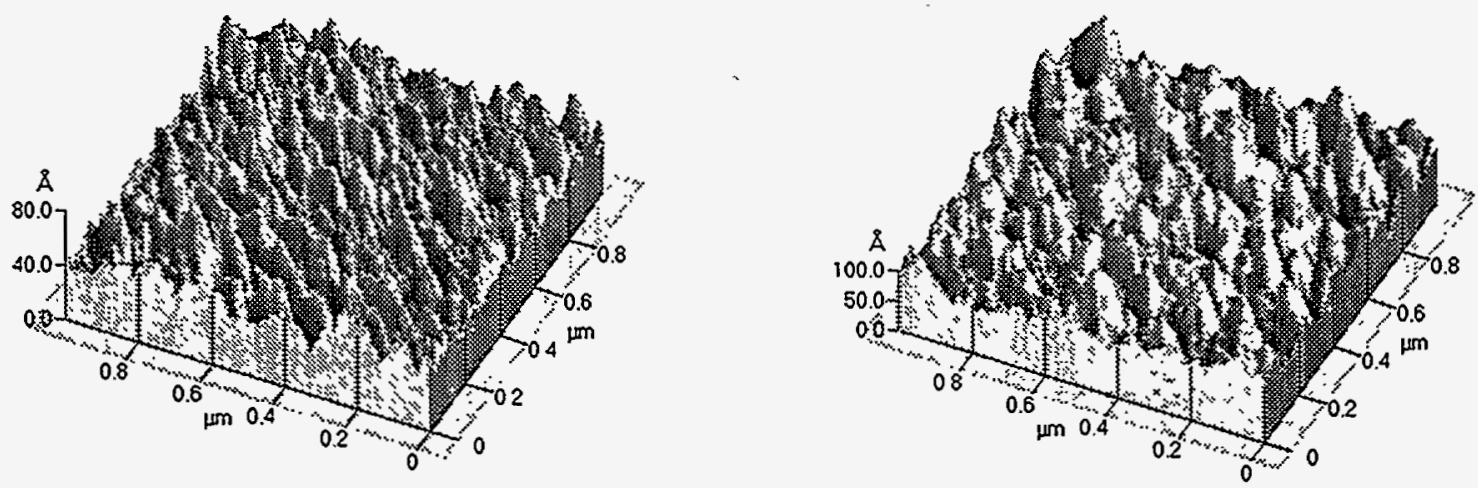

Figure 4. Surface image by $\mathrm{AFM}$ of $\mathrm{LiCoO}_{2}$ at a) $50 \mathrm{mT}$ oxygen pressure, rms roughness $8 \AA$; b) at $200 \mathrm{mT}$ oxygen pressure, rms roughness $19 \AA$

The optical indices for the optimum $\mathrm{Li}_{\mathrm{x}} \mathrm{CoO}_{2}$ film at $50 \mathrm{mTorr}$ are shown in Figure 5 for a series of lithiated states. They color anodically like $\mathrm{Li}_{x} \mathrm{Ni}_{1-x} \mathrm{O}$, but to a much lesser degree. $\mathrm{Li}_{x} \mathrm{CoO}_{2}$ could therefore serve as a counterelectrode to $\mathrm{WO}_{3}$ and even to other anodically coloring materials like $\mathrm{Li}_{x} \mathrm{Ni}_{1-x} \mathrm{O}$ because of its small coloration. Sputtered $\mathrm{Li}_{x} \mathrm{CoO}_{2}$ films could be colored but not bleached beyond their as-deposited state. ${ }^{10}$ It was speculated that Li deficiency in the films caused blockage due to substitutional Co atoms. Our films may have higher levels of $L i$ at the outset $(x=0.7$ by NRA). We also recorded one state with $L i$ levels less than $x=0.5$ which resulted in strong but irreversible coloration (Figure 5).
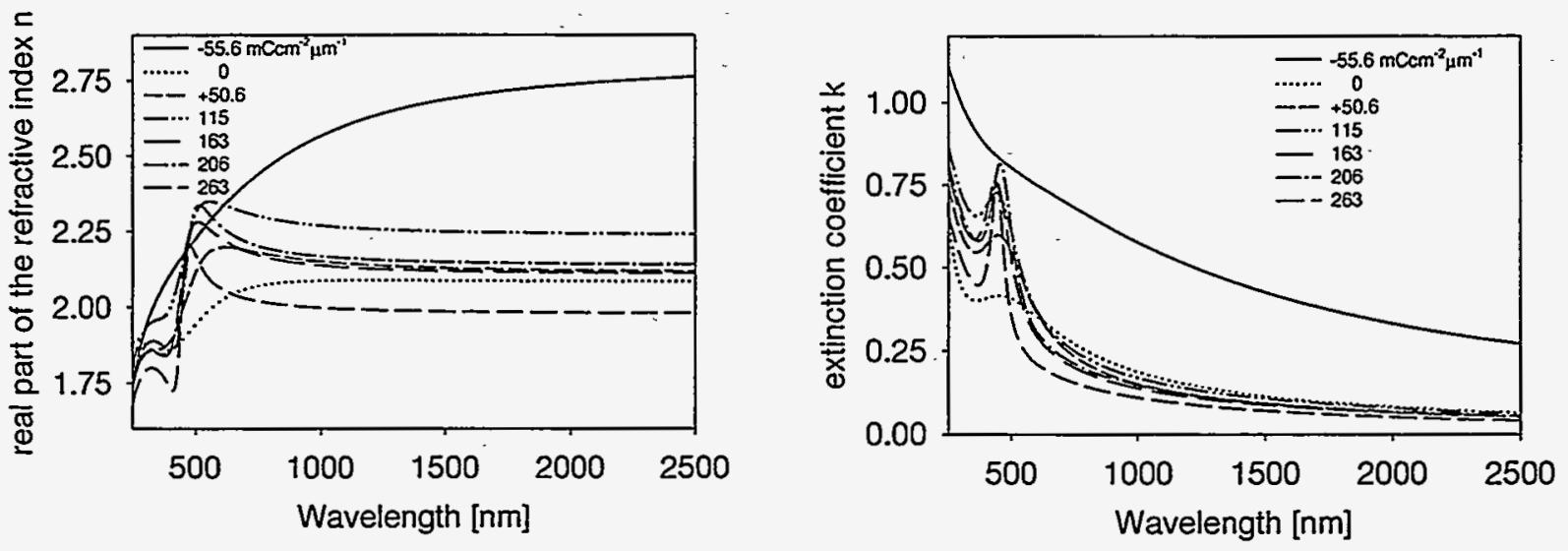

Figure 5. Optical indices of $\mathrm{Li}_{x} \mathrm{CoO}_{2}$ deposited by PLD at $50 \mathrm{mTorr} \mathrm{O}_{2}:$ a) real and b) imaginary parts:

\section{$3.5 \mathrm{~V}_{2} \mathrm{O}_{5}$}

$\mathrm{V}_{2} \mathrm{O}_{5}$ is a well known electrochromic material which has often been used as a counterelectrode to $\mathrm{WO}_{3}$. In this case the film was made by sol-gel techniques. The film whose optical index is given in Figure 6 is much rougher (164 $\AA$ ) than any of the others in this paper by vacuum deposition. This roughness is probably due to the sol-gel process itself as further indicated by the comparison between sol-gel and PLD-deposited $\mathrm{CeO}_{2}-\mathrm{TiO}_{2}$ below. A change from cathodic to anodic coloration is observed going down to the near ultraviolet as has consistently been reported ${ }^{11.12}$ These films, however, are not necessarily optimum or even typical. For example, the index of refraction of evaporated films was determined to be considerably lower than that of our films at $632.8 \mathrm{~nm}^{13}$ and from 600 to $2500 \mathrm{~nm} .{ }^{14}$ Also, the extinction coefficient estimated from many transmittance measurements varies widely in magnitude and shape, especially in the visible. 

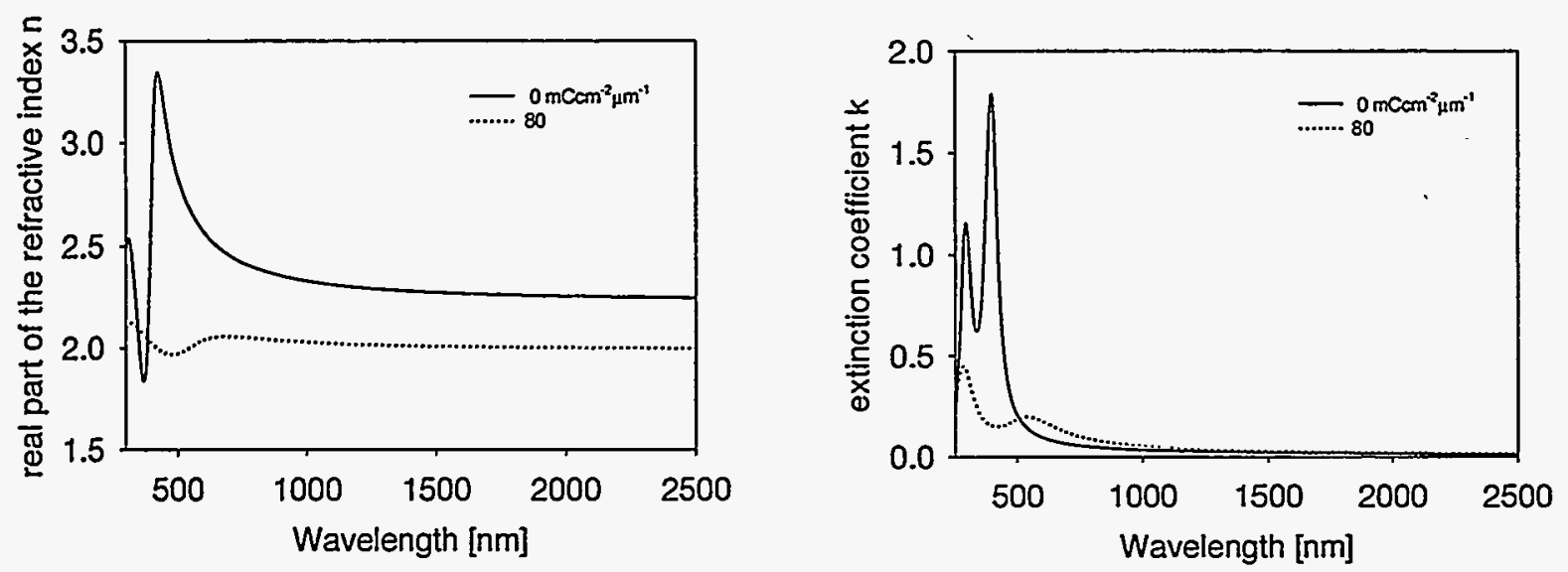

Figure 6. Refractive index of $\mathrm{V}_{2} \mathrm{O}_{5}$ : a) real and b) imaginary parts.

\section{$3.6 \mathrm{CeO}_{2}-\mathrm{TiO}_{2}$}

Another lithium counterelectrode of current interest is $\mathrm{CeO}_{2}-\mathrm{TiO}_{2 .}{ }^{15.16}$ In this case we made films of the stoichiometric composition by both PLD and sol-gel. The sol-gel films are much rougher than the PLD films as shown in Figure 7. In this case we obtained fairly poor agreement between the surface roughness predicted by the optical model and that derived from the AFM measurements. Further refinements to the model are probably necessary. The index of both films is similar and they follow classical normal dispersion forms: the indices decrease asymptotically towards higher wavelengths as in the case of $\mathrm{V}_{2} \mathrm{O}_{5}$ above, but without the fine structure. For the PLD film, $n=1.76$ at $550 \mathrm{~nm}$ and for the sol-gel film it is a bit higher at $n=1.83$. The films are slightly yellow with the fundamental absorption falling off to negligible levels by $450 \mathrm{~nm}$. At this point, it is difficult to know if these results are representative because so little information is available about the optical properties of $\mathrm{CeO}_{2}-\mathrm{TiO}_{2}$.
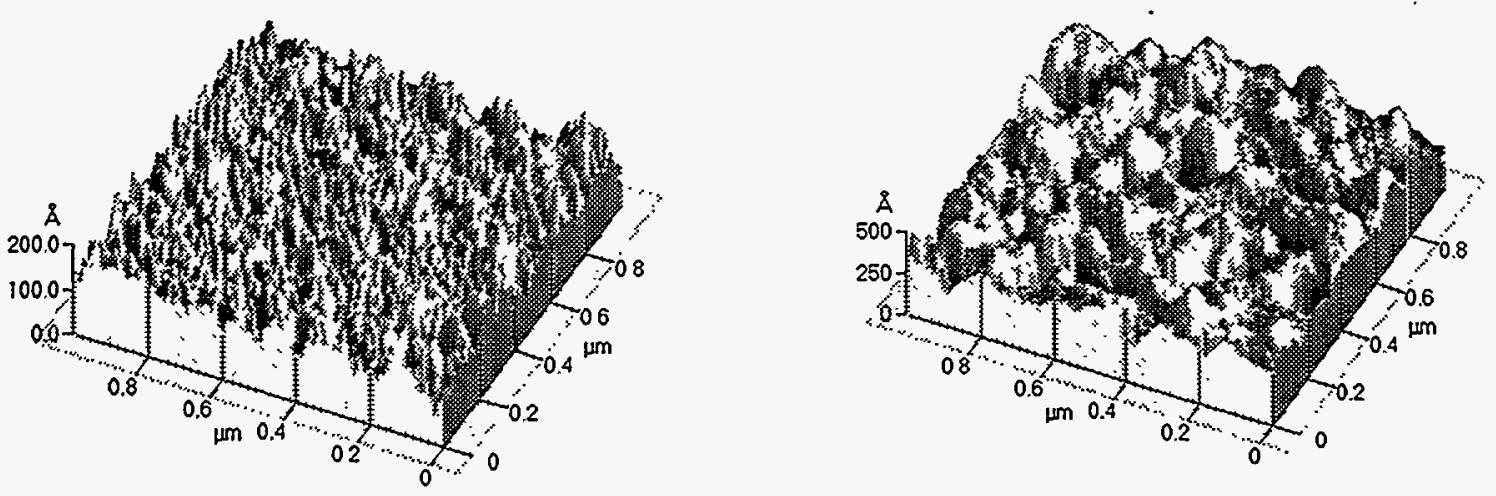

Figure 7. Surface image of $\mathrm{CeO}_{2}-\mathrm{TiO}_{2}$ by AFM: a) PLD, rms roughness $2 \mathrm{~nm}$; b) sol-gel, rms-roughness $5 \mathrm{~nm}$

\section{CONCLUSION}

Using relatively simple models of dispersion and structure, optical indices can be determined over a wide spectral range for a variety of electrochromic materials in different electrochromic states. Surface roughness can be accurately predicted as part of the optical model for most cases. At least for PLD films surface roughness is usually correlated with poor electrochromic performance and stability. Complete sets of optical indices are presented, suitable for design of advanced electrochromic devices.

\section{ACKNOWLEDGMENT}

This work was supported by the Assistant Secretary for Energy Efficiency and Renewable Energy, Office of Building Technology, State and Community Programs (BTS), Office of Building Systems of the U.S. Department of Energy under Contract No. DE-AC03-76SF00098. 


\section{REFERENCES}

' S. Selkowitz, M. Rubin, E.S. Lee, R. Sullivan, A Review of Electrochromic Performance Factors, Proc. SPIE Int. Symp. on Opt. Mater. Technol. (April 1994) Freiburg, Germany.

${ }^{2}$ K. von Rottkay, M. Rubin, S.-J. Wen, J. Kerr, T. Richardson, N. Ozer and J. Slack, presented at the $2^{\text {nd }}$ Int. Meeting on Electrochromism (IME-2) San Diego (September 1996).

${ }^{3}$ A. Yariv, Quantum Electronics, John Wiley \& Sons (-1975) p 57.

${ }^{4} \mathrm{~K}$. von Rottkay, M. Rubin, S.-J. Wen, Optical Indices of Sputtered $\mathrm{WO}_{3}$ over a Range of Coloration States, presented at the Int. Conf. on Metallurgical Coatings and Thin Films (April 1996) San Diego.

${ }^{5} \mathrm{~K}$. von Rottkay and M. Rubin, and P. Gerhardinger, Optical Indices Of Pyrolytic Tin-Oxide Glass, to be published in Proc. Mater. Res. Soc. (San Francisco April 1996),

${ }^{6} \mathrm{~K}$. von Rottkay and M. Rubin, Optical Indices Of Tin-Doped Indium Oxide And Tungsten Oxide Electrochromic Coatings, to be published in Proc. Mater. Res. Soc. (Boston, November 1995).

${ }^{7}$ F.K. Urban, P. Ruzakowski Athey and Md. S. Islam, Thin Solid films 253 (1994) 326.

${ }^{8}$ S.J. Wen, K. von Rottkay, M. Rubin, Electrochromic Lithium Nickel Oxide By Pulsed Laser Deposition, presented at the Electrochemical Society Meeting (San Antonio, Texas, October 1996).

${ }^{9}$ F. Decker, S. Passerini, R. Pileggi and B. Scrosati, Electrochimica Acta 37 (1992) 1033.

${ }^{10}$ G. Wei, T.E. Haas, and R.B. Goldner, Proc. Electrochem. Soc. 90-2 (1990) 80.

11 S.F. Cogan, N.M. Nguyen, S.J. Perotti and R.D. Rauh, J. Appl. Phys. 66 (1989) 1333.

${ }^{12}$ A. Talledo, C.G. Granqvist, J. Appl. Phys. 77 (1995) 4655.

${ }^{13}$ J.L. Ord, S.D. Bishop, and D.J. De Smet, J. Electrochem. Soc. 138 (1991) 208.

${ }^{14}$ L. Michailovits, I. Hevesi, L. Phan and Zs. Zarga, Thin Solid Films 102 (1983) 71.

${ }^{15}$ U.L. Stangar, B. Orel, I. Grabec, and B. Ogorvec, Proc. Soc. Photo-Opt. Instrumen. Engr. 1728 (1992) 118.

${ }^{16}$ P. Baudry, A.C.M. Rodriguez, M.A. Aegerter and L.O. Bulhoes, J. Non-Cryst. Solids 137 (1990) 319. 